\title{
The Effect of Service Compact (SERVICOM) on Service Delivery in Nnamdi Azikiwe University Teaching Hospital Nnewi, Nigeria
}

EMEULU, Jude K | MUO, M.C | CHUKWUEMEKA, E.E.0

\section{Abstract}

$T^{\mathrm{s}}$

study examined the effect of

service compact (Servicom Service delivery) in Nnamdi Azikiwe University Teaching Hospital Nnewi. Questionnaire and face-to-face interviews were used in the collection of data. The hypotheses were tested using descriptive statistics. The study discovered among other things that with the inauguration of the SERVICOM Charter by the Federal Government of Nigeria, the Management of Nnamdi Azikiwe University Teaching Hospital Nnewi identified key areas that required re-evaluation and attention based on the submissions of every service unit and department, after an analysis of the Strengths, Weaknesses, Opportunities and
Threats (SWOT) of each of the service areas. A pre-SERVICOM Charter workshop which was supervised by the Federal Government was held in the various institutions nationwide to enable care providers enumerate their current service capacity and identify their impediments. In the light of the foregoing, some of the recommendations proffered are that the SERVICOM Charter project should be sustained and supervision and control of the SERVICOM Charter project should be intensified in order to ensure that the Nigerian factor of service-fatigue would not supervene in care delivery in the near future.

Keywords: Service delivery, performance, client, Service Compact, SERVICOM 


\section{Introduction}

Public services in Nigeria have over the years acquired the reputation of poor performance, and this is irksome in the health sector. On $21^{\text {st }}$ March, 2004, the Federal Government introduced the SERVICOM Charter, a unilateral resolve to improve public service delivery to the nation's citizens by structural improvement and attitudinal change (SERVICOM, 2003:1). On 10 th May, 2005, the Nnamdi Azikiwe University Teaching Hospital (NAUTH), Nnewi, Anambra State, Nigeria adopted this Charter for healthcare delivery. This study is a retrospective evaluation of the effect of the SERVICOM Charter on the institution seven months before its adoption in 2005 to the year 2009, when this evaluation was carried out.

\section{Statement of the Problem}

Nigeria's legendary poor health sector has been discussed at various fora over the past 30 years even before the military coup of $31^{\text {st }}$ December, 1983 , which actually gave as one of the reasons for that putsch as "our hospitals have become mere consulting clinics" (Global Security 1983: 14; THIS Day Newspapers 2009 :5). For these past decades, the World Health Organization (WHO) has rated the Nigerian health sector very low, more so with the consistently low budgetary allocations to the sector by successive government administrations. Nigeria is rated among the "Low-expenditure, Low-growth, Health Economies" all of which have a total population of about 2.6 billion people (43\% of the world population), but yet, have a scandalously disproportionate $5 \%$ of the world's health expenditure (UNDP, 2006: 12). Countries in this group suffer from an absolute under-funding of their health sector, along with a disproportionally high disease burden.

In most health institutions in Nigeria, the attitude of workers was taking a huge toll on the provision of optimal health care delivery for the unfortunate citizens. The health workers' careless and carefree attitudes towards public institutions and government property were nationally pervasive and disruptive of the government's intentions of healthy life for its citizens. Starting from the point of reception of clients who come with health challenges, to the available gadgets and facilities, through the waiting time for medical examination and laboratory investigations, to the point of treatment and drug dispensing, perennial complaints of delays, uncouth attitude, impoliteness, lack of communication, lack of compassion and at times, shameful, corrupt sharp practices, were 
peculiar trademarks. Hospital equipment were obsolete, and the workers skills, in tandem with their obsolete tools, were expectedly out of date and anachronistic too.

On account of these attitudinal challenges from public health workers, clientele satisfaction and patronage, revenue generation, public rating and self-sustenance in public institutions rank rather low all over the country. Practically, no public institution has been self-sustaining, but not only that, the low clientele attendance made it increasingly difficult to hold hands-on training for all cadres of health workers - medical, laboratory, nursing, physiotherapy, etc. All of these were further impacting negatively on the overall quality of training, as there are seemingly not enough clients with whom to learn the art and science of healthcare delivery, for the different cadre of workers. Without a good public image, expectedly, revenue generation, infrastructural development and capital investment in the health sector became a far cry from what is obtained internationally, and what is expected of the country. According to the Central Intelligence Agency Report (2012:16), Nigeria is ranked by 2010 estimates of 2.341 million barrels per day, as the world's $5^{\text {th }}$ largest exporter of crude oil, and with stores of 5.153 trillion $\mathrm{m}^{3}$ she is rated as having the world's $9^{\text {th }}$ largest reserve of natural gas. Despite her natural endowments, the most populous black nation, was fast becoming the laughing stock of the rest of the world, and was already an embarrassing commentary to the aspirations of equality for the entire black race.

From the perspective of the principles of public administration, it could be readily deciphered that these shortcomings bothered mostly on the management of both the material and human resources meant to direct resources of the tertiary health institutions towards the satisfaction of the clients' needs and expectations for attending these institutions for specialist healthcare. According to Flippo (1981: 141), human resources management is the planning, organizing, directing and controlling of the procurements, development, compensation, integration, maintenance and separation of human resources to the end that individual, organization and societal objectives are accomplished. Abah (1997:7) and Orga (2002:27), both agree, to a large extent, with this definition. Orga (1997) further enumerated personnel administration to include recruitment, selection, orientation, placement, training and development, motivating and enumerating the employees.

If these contentions are correct, then, it could be safely summarized that Nigeria's failed health services, just like most of the other public institutions, could be tied directly 
to the failed human resources management process. As a result, the likely measures to reverse the drift in quality service delivery could only come from a revision of the human factor in all Nigeria's public institutions, not least, the healthcare sector. Nigeria's Federal Government must have identified these factors which consequently prompted a radical review of the human factors at play in her public institutions and resolved on the project of its revival. The SERVICOM Charter fully captured the elements for such personnel reorientation. Yet, it may not be as simple as that because, according to Chukwuemeka (2004:8), personnel or human resources management is one of the most complex and challenging fields of endeavour. This is reasoned along the line that, not only must the organization's requirements for an effective work force be met, the personnel manager must also be greatly concerned with the expectations of both employees and society in general. This implies, therefore, that in trying to achieve the set goals of the organization or institution, the welfare of the human factors therein should not be relegated to the background; it must be taken into very serious considerations. Employee satisfaction should be as relevant as client satisfaction if the realization of the organizational or institutional goals should be thought of as achievable.

On account these self-evident shortcomings, the government decided to embark on a civic revolution in all its public services, starting with the introduction of mandatory attitudinal change for all health workers, using the instrument of the SERVICOM Charter, to make an attempt at remodelling the disposition of these workers towards their clients and institutions, in order to save the public health sector from total collapse. Interestingly, prior to these changes, the government had increased the emoluments of her workers in the public sector, after a protracted negotiation with the organized labour.

\section{The SERVICOM Charter}

On 21 ${ }^{\text {st }}$ March, 2004, the Federal Government of Nigeria resolved to enter into a "SERVIce COMpact" (SERVI-COM) with the citizens of our country for a commitment to their welfare and satisfaction with service delivery; and thus, was born the SERVICOM Charter (SERVICOM, 2003:2). By SERVICOM, it was agreed that all Ministries, Parastatals and Agencies and all other Government Departments will prepare and publish, not later than the First Day of July 2004, SERVICOM CHARTERS whose provisions would include: 
- quality services designed around the requirements of their customers and served by staff sensitive to the needs of their clients;

- set out the entitlements of the citizens clearly and in ways they could readily understand;

- the list of fees payable (if any), and the prohibition of the demand of any additional payments;

- commitment to the provision of services (including the processing of applications and the answering of correspondence) within realistically set timeframes;

- details of agencies and officials to whom complaints about service failures may be addressed;

- $\quad$ publish these details in conspicuous places accessible to the public;

- periodically conduct and publish surveys to determine levels of customer satisfaction. (SERVICOM, 2004:2)

On 10 $10^{\text {th }}$ May, 2005 the Nnamdi Azikiwe University Teaching Hospital Nnewi finally adopted the SERVICOM Charter in the provision of services to her clientele, and began to do everything in a slightly different way (Appendices I - IV). But, it had always been known that putting people first as the focus of service delivery reforms was not a trivial principle, as it could require significant - even if often simple - departures from "business as usual."

In order to evaluate the effect of these novel SERVICOM Charter measures, this study which is a retrospective evaluation, was designed to analyze the clientele turnover as well as the outcome from the various cases treated in NAUTH Nnewi after the introduction of the SERVICOM Charter. These data were then compared with figures registered prior to the introduction of the Charter in the institution in order to assess the effect of this Charter on the provision of services in the tertiary health institution. With these, the usefulness, or otherwise, of the SERVICOM Charter in the improvement of healthcare delivery to the catchment population of NAUTH, could be reasonably determined. 


\section{Objectives of the Study}

- To ascertain the average turnover of clients in NAUTH prior to the 2005 launch of the SERVICOM Charter and if there were any changes in the turnover of clients between the pre-SERVICOM Charter year of 2005 and the postSERVICOM Charter period, in the years after 2005 at the various units.

- To ascertain if there were changes in the effectiveness and quality of service delivery pre-SERVICOM Charter and post-SERVICOM Charter as mirrored, amongst other parameters, by the number of deaths amongst the clients [mortality rate] and to ascertain if there were changes in birth and death rates among the obstetric clients who had deliveries in NAUTH Nnewi, as an indirect reflection of the quality of care delivery amongst pregnant clients.

- To determine if or not there was an overall improvement of indices in health care delivery in NAUTH after the introduction of the SERVICOM Charter.

\section{Research Questions}

The study is guided by the following research questions:

- What was the average turnover of clients in NAUTH in 2005 before the SERVICOM Charter took effect?

- Were there any changes in the turnover of clients between the pre-SERVICOM Charter year of 2005 and the post-SERVICOM Charter period, in the years after 2005 at the various units?

- Were there changes in the effectiveness of service delivery pre-SERVICOM Charter and post-SERVICOM Charter as mirrored, amongst other parameters, by the number of deaths amongst the clients?

- Were there changes in birth and death rates among the obstetric clients who had deliveries in NAUTH Nnewi, as an indirect reflection of the quality of care delivery amongst pregnant clients?

- Was there an overall improvement of indices in health care delivery in NAUTH after the introduction of the SERVICOM Charter or not? 
The Effect of Service Compact (SERVICOM) on Service Delivery in NAUTH Nnewi 107

\section{Research Hypotheses}

\section{Alternative Hypothesis, $\mathrm{H}_{1}$}

- A positive change in the facilities in the institution and attitude of health workers following the introduction of the SERVICOM Charter has improved service delivery in government health facilities.

\section{Null Hypothesis, $\mathrm{H}_{0}$}

- There was no positive change in the facilities in the institution, attitude of health workers and service delivery in government health facilities following the introduction of the SERVICOM Charter.

\section{Review of Empirical Research}

The World Health Organization (WHO), in these past decades, has rated the Nigerian health sector very low, more so with the consistently low budgetary allocation to the sector by successive government administrations. Nigeria is rated among the "LowExpenditure, Low-Growth Health Economies," a group of underdeveloped countries which despite comprising a population of 2.6 billion people (about $40 \%$ of the world's population), is unfortunately credited with less than $5 \%$ of the world's health expenditure [WHO 2008]. Countries in this group suffer from an absolute under-funding of their health sector, along with a disproportionally high disease burden. From 1997 to 2001, Nigeria's total annual budgetary allocation to health tottered around $1.7-2.3 \%(2.1 \%$, $2.3 \%, 1.7 \%, 1.7 \%$ and $1.9 \%$, respectively), compared to Cameroon 4.1 - $7.9 \%$, South Africa 10.9 - 12.4\%, Namibia 12.4 - 13.1\%, Canada 13.9 - 16.2\%, and USA 16.8 - 17.6\%, in the same period. Meanwhile, the WHO prescription was $15 \%$ of the Annual National Budget of all member countries (WHO 2004, NHA 2008). By 2011, Nigeria's budgetary health expenditure had inched up to $5.3 \%$, still far lower than the figures from all her neighbours, and other sub-Saharan African contemporaries (CIA, 2012: 10). And, no matter how one looked at it, the human health indices from our country were all very demoralizing.

According to the same CIA Report (2012), the population growth rate was $2.54 \%$, birth rate was 38.8 births $/ 1,000$ population, and death rate was 13.2 deaths $/ 1,000$ 
population, the $18^{\text {th }}$ highest in the world. The country's maternal mortality rate was $11^{\text {th }}$ highest in the world at 630 deaths/100,000 deliveries, with an infant mortality rate of 73 deaths 1,000 live births, the $15^{\text {th }}$ highest in the world. Life expectancy in the country, which stood at 52.5years, was the $211^{\text {th }}$ in the world, whereas the adult prevalence rate of HIV/AIDS by the 2009 estimate was $3.6 \%$, the $17^{\text {th }}$ highest in the world, and 3.3 million people in the country lived with HIV/AIDS, the $2^{\text {nd }}$ highest in the whole world. It looked like Nigeria's wellbeing and health indices were the highest for the bad parameters and lowest for the good parameters. It's no wonder that the alarming crises in health indices in the country was an offshoot of a two-decade long neglect of the health sector in the annual budgetary allocations by the successive military governments that held the country in an iron grip, in that period.

The 2003/2004 Nigerian Living Standards Survey (NLSS) conducted by the Nigerian National Bureau of Statistics, with international technical assistance, documented a national poverty rate of $54.4 \%$, implying that more than half of Nigerians live on less than $\$ 1$ per day, as against the WHO stipulation of $\$ 5$ [Sanders 2008]. And even a whole decade later, the allocations to health for 2010, 2011 and 2012 were still as low as 4\%, $5.3 \%$ and $5.95 \%$, representing $27 \%, 33 \%$ and $39.6 \%$ of WHO recommendation, respectively (Health in Africa 2012). In other words, at no time in the past 20years has Nigeria's annual budgetary allocation to health (1.7\% to $5.95 \%$ ) ever gotten up to $40 \%$ of WHO recommendation, when smaller and less endowed countries like Cameroon and Namibia made it to $60-90 \%$ in the same period. It was an extremely embarrassing situation for a country that touts itself nationally as the Giant of Africa.

In December 2003, a research project was commissioned to review service delivery in Nigeria with a view to determining the:

- institutional environment for service delivery,

- citizen's views on (and experiences with) service delivery, and

- designing of a roadmap for a service delivery programme.

Following this research project, a report titled "Service Delivery in Nigeria: $A$ Roadmap" was published in February 2004, and in March 2004, a Special Presidential Retreat was held to deliberate extensively on this report. At the end of the Retreat, the Federal Government on $21^{\text {st }}$ March, 2004, resolved to enter into a "SERVIce COMpact" (SERVI-COM) with the citizens of our country, for a commitment to their welfare and 
satisfaction with service delivery. Thus, was born the SERVICOM Charter (SERVICOM 2003: 4), which became upgraded to a policy agenda, and subsequently became a government policy for all public institutions to abide by.

\section{Synthesis of Literature Review}

The synthesis of this literature review revealed that healthcare delivery in Nigeria is way below the international standards prescribed by the WHO. The major culprit in all of these has been the Federal Government of Nigeria which has perennially kept budgetary allocation to the health sector far below the $15 \%$ stipulated by the $\mathrm{WHO}$, and there does not seem to be an end in sight to this horrendous anomaly. In the past 20years, budgetary allocation to health has hovered most unfortunately between $1.7 \%$ and $5.95 \%$. The direct consequence is the precipitous fall in health standards as mirrored by the various health indices, including a progressive drop in life expectancy of the average Nigerian.

Perhaps, worried by these appalling statistics, the Federal Government, following the examples of other nations, decided to undertake a re-appraisal of the health sector as part of the larger project of system re-positioning. The Government chose to start with the upgrading of facilities in the nation's public institutions, followed by an attitudinal reorientation of all her civil and public servants, in order to re-brand all her institutions, not least, those in the health sector. Most of the facility upgrade was half-hearted and unconvincing, and their influence on the morale of public and civil servants is, yet, indeterminate. Many opinions have pointed at the shortcomings imposed on public service by bureaucratic bottlenecks which have left virtually all public institutions in dire straits. Appropriate sanctions for defaulters were equally put in place in the SERVICOM Charter, while appropriate lines of complaint and command were equally established in order to ensure that every dissatisfied client should be able to make an appropriate representation to right a wrong protocol and address the issue of clients' satisfaction as a way to measure and boost performance and efficiency.

In Nnamdi Azikiwe University Teaching Hospital Nnewi, before the full implementation of the SERVICOM Charter, the different service units and departments of the institution were requested to critically analyze their capacities and potentials using the Strengths-Weaknesses-Opportunities-Threats (SWOT) Analysis template. Following this institutional self-evaluation, each of the units and departments was able to articulate 
its service capacities and challenges. Each of them then stated its vision and mission for service delivery, and had them visibly displayed at strategic points in the units and departments, all around the tertiary health institution (Appendices III \& IV). It was simply a self-appraisal framework that facilitated an objective and dispassionate in-house appraisal of individual service units and departments in order to determine the aspects of their services that could be encouraged and invested in, and the aspects that could be modified in order to ensure an optimal client satisfaction and patronage, bringing them up to the minimum acceptable standards. The publicly displayed service notice of each unit or department, besides announcing its capacity in the provision of health services, and their vision as well, also left the relevant telephone numbers and designations of officers of the department to whom complaints of extortion, rude response to enquiries and the host of other negative attitudes of public servants should be promptly reported in order to ensure that not only would good attitudes be enforced as a means of engendering client satisfaction by the public servants, but that erring public servants amongst them are commensurably sanctioned. These persons to whom reports could be made are known as SERVICOM nodal officers.

\section{Research Design}

This study adopted the ex-post facto research design, which according to Akuezilo and Agu (2002:10) seeks to find out factors that are associated with certain occurrences, outcomes, conditions or types of behaviour analysis of past events. Chukwuemeka (2006: 19) referred to the ex-post facto research design as a form of descriptive research model in which independent variables have already occurred and in which an investigator starts with the observation of dependent variables, and then, studies the independent variables in retrospect, for their possible relationship to have any effect on the dependent variables. Muataz and Shawqi (2006:44) used this design in studying the outcome of adolescent pregnancy in University of Jordan from 1991 to 2000.

In this study, the independent variables include client turnover at the various service points like the Accident and Emergency Unit, Out-patient Department, Consultants' Clinics, Operating Theatres, Labour Rooms, Wards, Children Out-patient Unit and Laboratories (Appendices $\mathrm{V}$ - XIII). These are the occurrences that preceded the study and beyond the influence or manipulation of the researcher who was evaluating the 
attitudinal and structural changes introduced by the SERVICOM Charter, in an attempt to determine the relationship between the independent and dependent variables. Therefore, the ex-post facto research design is appropriate for this study.

\section{Population of the Study}

The population of this study was 642,280 subjects obtained by retrieving the medical records of all the patients enrolled into treatment at the various service points in Nnamdi Azikiwe University Teaching Hospital (NAUTH) Nnewi from 2005 to 2009, in the various service units of the hospital. The researcher chose NAUTH because it was the main referral Centre in Anambra State and the $2^{\text {nd }}$ of the two major referral centres in the whole of South-East Zone of Nigeria, which is composed of five States.

\section{Sample and Sampling Technique}

The sample population used was the already registered hospital clients in some of the service points of the hospital; and since these records were already documented for the said period (2005 - 2009) there was no need to apply any other sampling technique.

\section{Sources of Data}

Hospital Records viz. Central Records Unit, General and Children Out-patient Clinics, Accident and Emergency Unit, Medical Laboratories, Operating Theatres, Labour Room and Specialty Clinics constituted all the sources of data.

\section{Instrumentation}

The instrument of data collection was the clients' hospital records from 2005 to 2009, and the central records pool of the Hospital's Department of Health Records and Statistics. The collected data were then uploaded electronically on Microsoft Excel Broadsheet work template which was subsequently used in data collation and data analysis. 


\section{Validity of the Instrument}

The record used to generate data contained the same data base as those used in collecting the hospital records (Appendices VI - XI). The consent of the Medical Records Department was then sought for within the study period and the Department then, certified the accuracy and validity of the format.

\section{Reliability of the Instrument}

The format used is a standardized instrument of the Nnamdi Azikiwe University Teaching Hospital Nnewi (Appendices V1-XI), and as long as it is the only official instrument of the hospital, it is regarded as a reliable instrument.

\section{Method of Data Collection}

The hospital records of all the clients registered in the General Out-Patients Department, Consultants Clinic, Accident and Emergency Department, Labour Room and Wards of Nnamdi Azikiwe University Teaching Hospital Nnewi in 2008 and 2009 were collected using Microsoft excel Broad Sheet and then, the records of those registered from 2005 to 2007 were also collected for comparison. Details of deaths (mortality), births and complications (morbidity) from the different service units were collected (Appendices $V$ XIII). The registers of the Department of Health Records and Statistics were used to crosscheck data.

\section{Data Presentation and Analysis}

The number of client registrations, new births, complicated cases, deaths were converted to percentages and represented on frequency tables. Bar charts, histograms and pie charts were also used to represent some of the data. Statistical analysis was then done using the chi-square; with $p$-value $\leq 0.05$ taken as significant.

The distribution of the data was as follows: 
The Effect of Service Compact (SERVICOM) on Service Delivery in NAUTH Nnewi 113

Table 1: Annual Distribution of Attending Clients

Year

No. of Attending Clients

2005

80,604

2006

113,324

2007

138,737

2008

150,961

2009

158,654

Total

642,280

\section{Data presentation and analysis}

By the end of 2006, numerical data from the hospital began to show a change in all facets of care delivery compared to the figures in the preceding year, and quite remarkably so.

In this study, data collected on the service performance and clientele turnover in Nnamdi Azikiwe University Teaching Hospital Nnewi for the year 2005 were largely regarded as reflecting the situation in the pre-SERVICOM Charter era, whereas data collected for 2006 and 2007 were presumed to reflect the transition phase of the SERVICOM Charter, and data from 2008 and 2009 were taken to reflect the established performance in the SERVICOM Charter era.

The reason for this classification was that the SERVICOM Charter was launched in the hospital by mid-2005, and it took the rest of 2005 to 2007 to ensure that its awareness campaign spread round the institution for a full comprehension and acceptance by all the members of Staff, which period was therefore reflective of a transition phase. Then the latter years (2008 and 2009) were regarded as the period of full establishment and acceptance of the SERVICOM Charter.

The attendance to the Consultant Out-patient Clinics for the years 2005, 2006, 2007, 2008 and 2009, were 36032, 48703, 58530, 64931 and 66831 clients, respectively (Figure 1); whereas, attendance to the General Out-patient Clinics for the same period were 
35866, 51520, 57830, 60056 and 62055, respectively (Figure 2). When these were subjected to statistical analysis with chi-square test, the differences between the figures for 2005 and those for 2006, 2007, 2008 and 2009, respectively were all statistically significant both for the Consultant and General Out-patient Clinics, respectively, ( $p$-value was $\leq 0.05$ in each of 8pairs of variables that were evaluated for the years of transition to the SERVICOM project, 2006 and 2007).

Figure 1: Attendance to Consultant Out-Patient Clinics

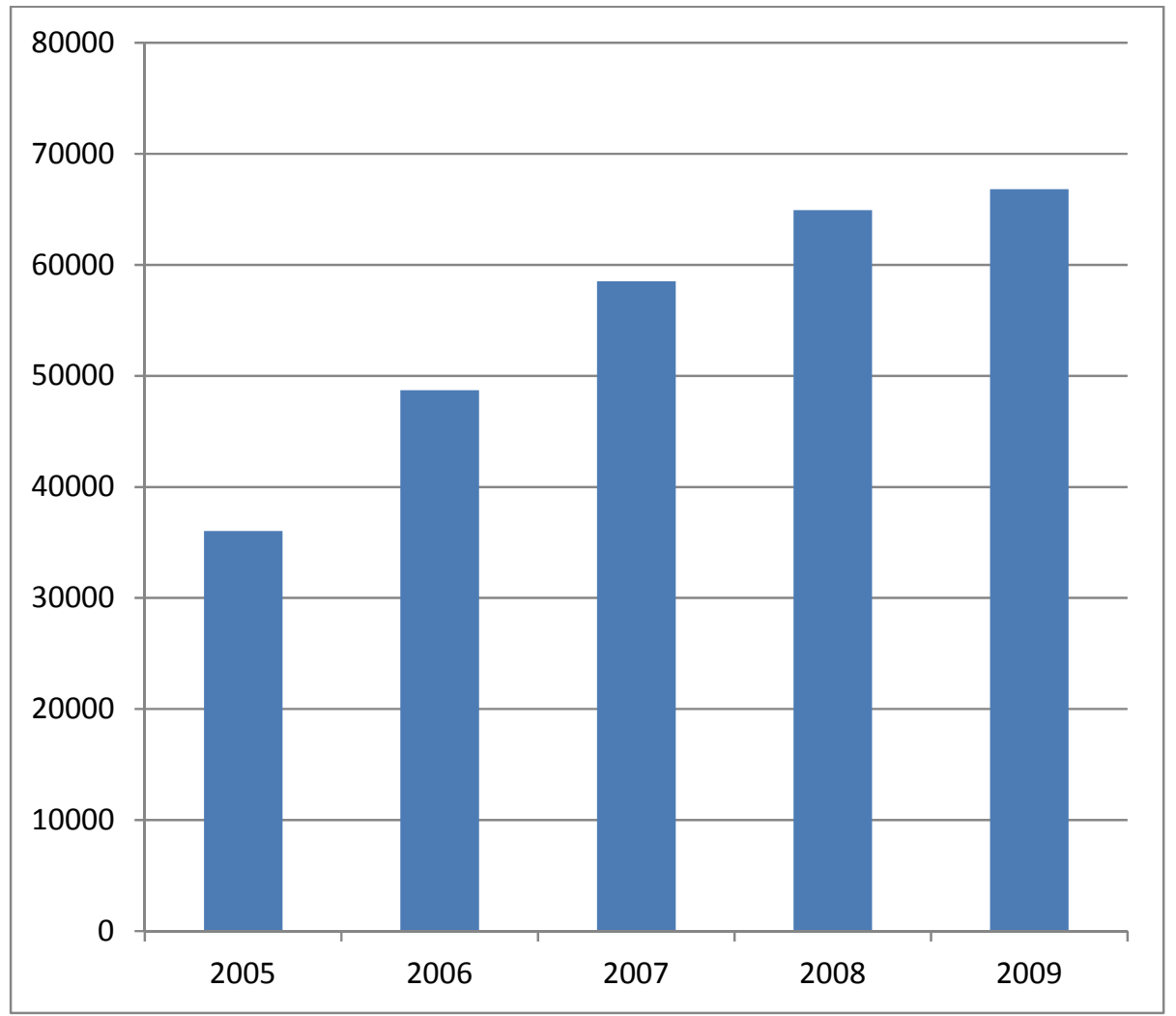

The attendance to Consultant Out-patient Clinics for the years 2005, 2006, 2007, 2008 and 2009 were 36032, 48703, 58530, 64931 and 66831 clients, respectively. 
Figure 2: Attendance to General Out-Patient Clinics

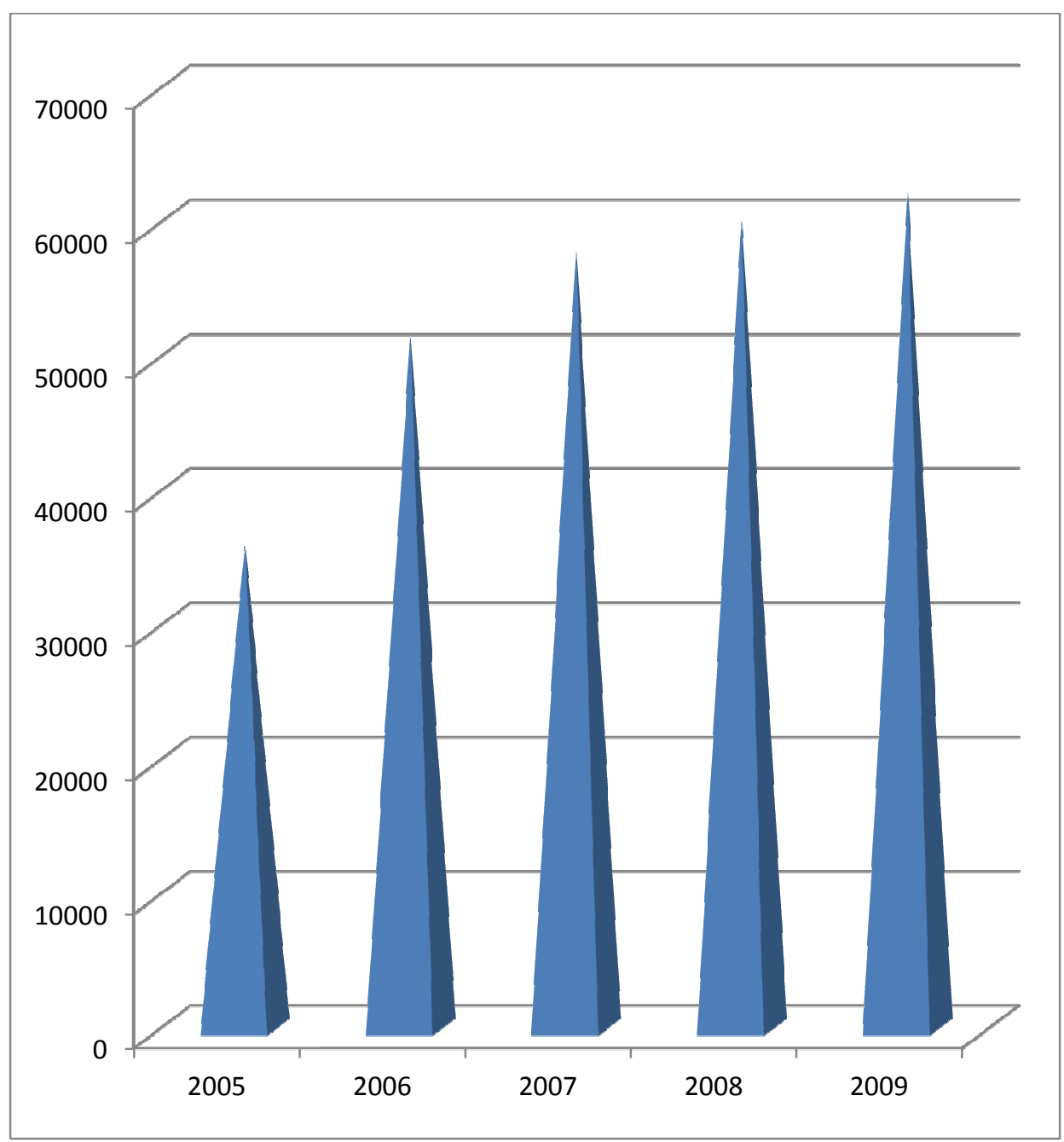

Attendance to the General Out-patient Clinics for the same period 2005, 2006, 2007, 2008 and 2009 were 35866, 51520, 57830, 60056 and 62055, respectively.

In the Children's Out-patient Clinics, attendance for the same years were 36032, 48703, 58530, 64931 and 66831 (Figure 3); and for the Accident and Emergency Unit they were 3988, 7034, 10503, 12224 and 14118, respectively (Figure 4). 
Figure 3: Attendance to Children's Out-Patient Clinics

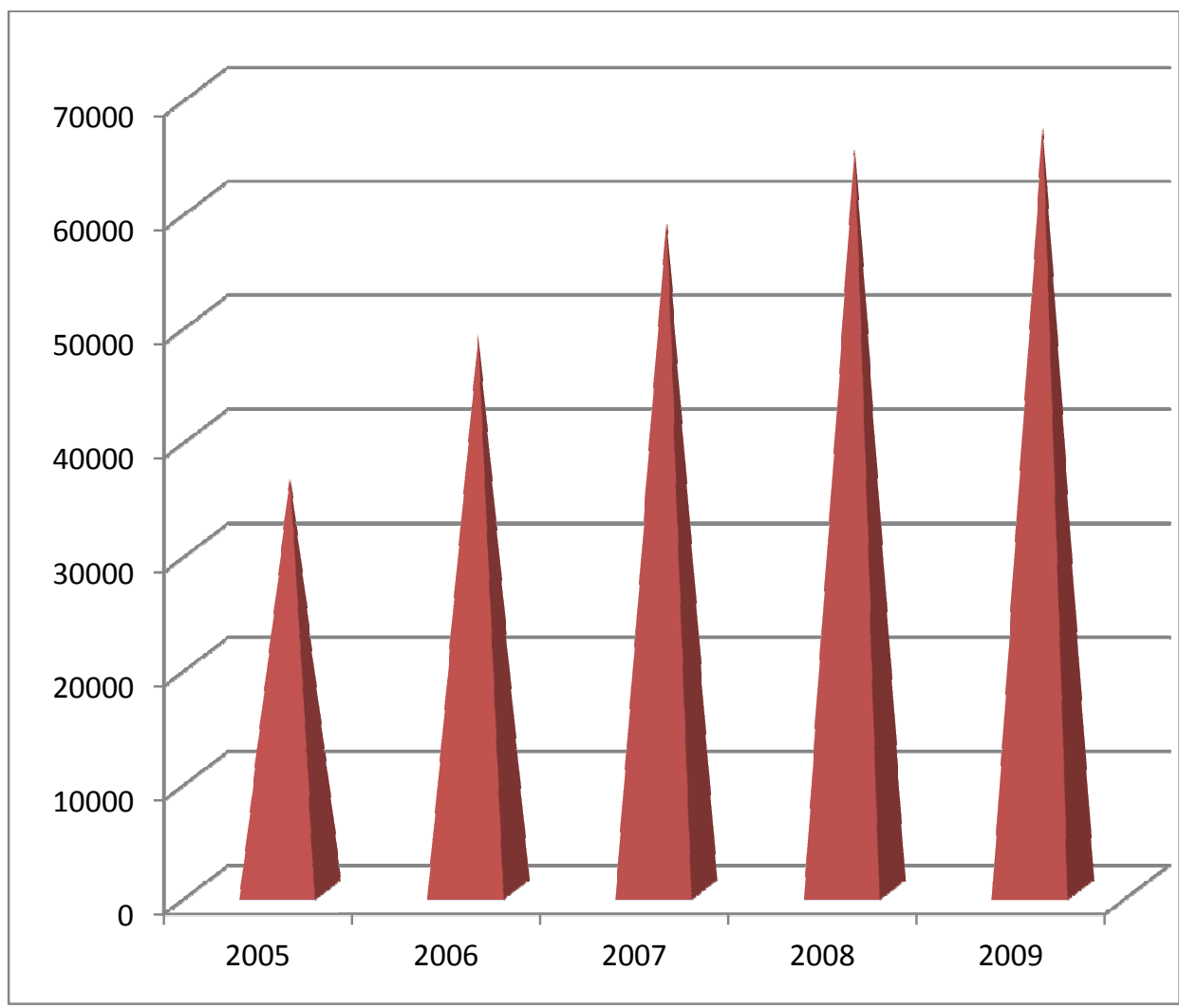

Attendance to Children's Out-patient Clinics were 36032, 48703, 58530, 64931 and 66831, for the years 2005, 2006, 2007, 2008 and 2009, respectively.

In the Accident \& Emergency Unit, the clientele attendance of 3988, 7034, 10503, 12224 and 14118 for the same period equally translated to rises of $76.4 \%(p<0.05)$, $163.4 \%(p<0.05), 206.5 \%(p<0.05)$ and $254 \%(p<0.05)$, respectively over the 2005 figures. 
Figure 4: Accident and Emergency Cases

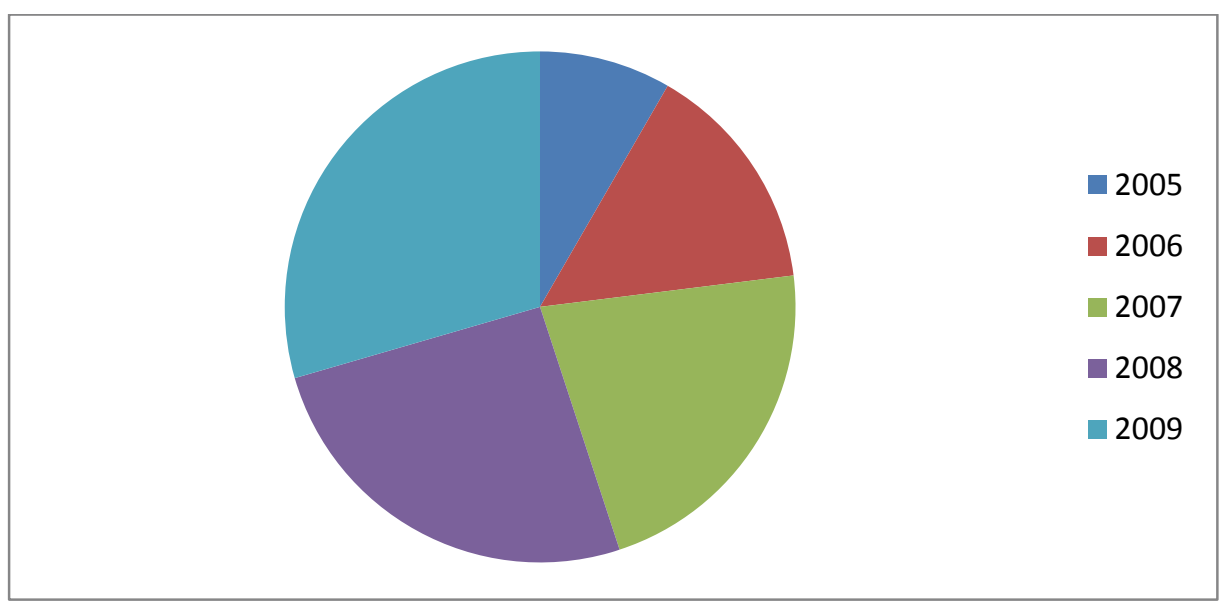

The Accident and Emergency Unit clientele were 3988, 7034, 10503, 12224 and 14118 for the study period.

The Hospital In-patient Admissions for the years under study 2005, 2006, 2007, 2008 and 2009, were 4718,6067, 11874, 13750 and 15650, respectively, see Figure 5.

\section{Figure 5: In-Patient Admissions}

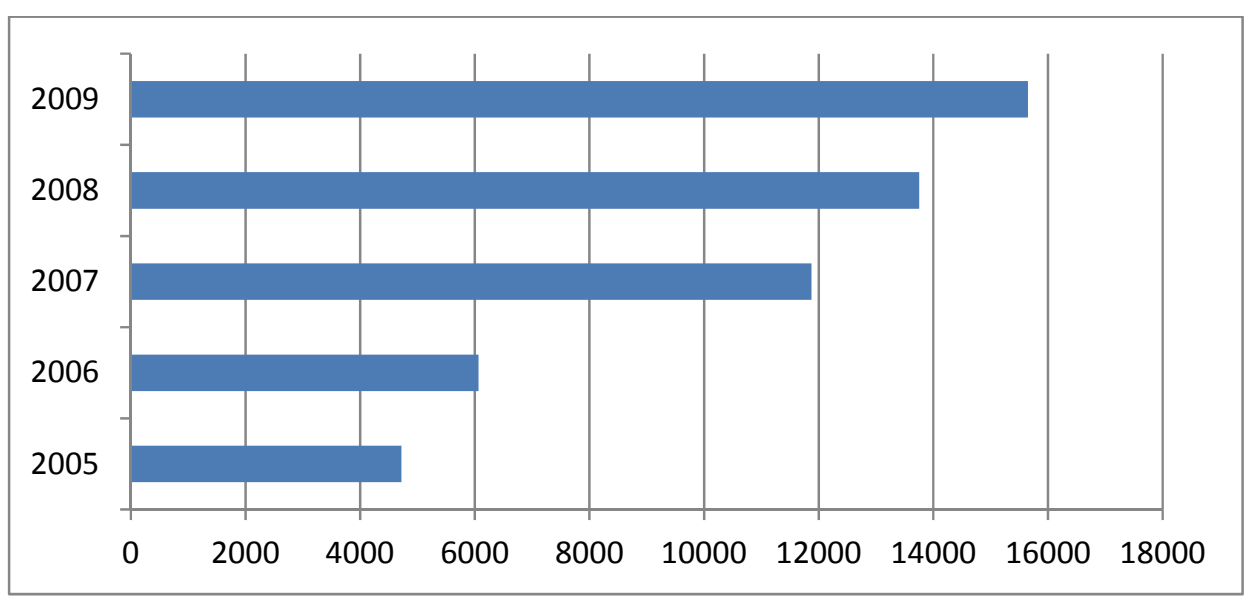

The Hospital In-patient Admissions were 4718, 6067, 11874, 13750 and 15650 in the period under study, 2005, 2006, 2007, 2008 and 2009. 
Registrations for clients for Laboratory Services for the same period were 58039, $62007,81196,93300$ and 115301 representing differences of $6.83 \%, 39.9 \%, 60.8 \%$ and 98.7\%, respectively of 2006, 2007, 2008 and 2009 over the 2005 figure of 58039, see Table 2.

Table 2: Laboratory Services

Year Total Laboratory Clientele Patronage Increase over 2005

(No. of Clients in $2005=58039)$

2006

62007

(3968) $\quad 6.83 \%$

2007

81196

(23157) $39.9 \%$

2008

93300

$(35261) \quad 60.8 \%$

$\underline{2009}$ 115301 (57262) $98.7 \%$

Laboratory Services 58039, 62007, 81196, 93300 and 115301

The Surgical Operations in the Theatres were 1001, 1321, 3706, 4142 and 5642 (Table 3), inclusive of both elective and emergency surgical cases, and Baby Deliveries in the Labour Room were recorded as 596, 627, 1611, 2936 and 2123, for the study periods of 2005, 2006, 2007, 2008 and 2009, respectively as shown in Table 4. 
The Effect of Service Compact (SERVICOM) on Service Delivery in NAUTH Nnewi 119

Table 3: Surgical Operations in the Theatres

Year

No. of Operations

Increase over 2005

(Total No. for $2005=1001$ )

2006

1321

(320)

$32 \%$

2007

3706

(2705)

$270.2 \%$

2008

4142

(3141)

$313.8 \%$

2009

5642

(4641)

$463.6 \%$

Surgical Operations in the Theatres 1001, 1321, 3706, 4142 and 5642

Table 4: Baby Deliveries and Maternal Mortality

Year No. of Deliveries Increase over $2005 \quad$ Maternal Mortality (\%)

(Deliveries in $2005=596)$

(Mortality in $2005=(11) 1.84 \%)$

\begin{tabular}{llll}
2006 & 627 & $(31) 5.2 \%$ & $(9) 1.43 \%$ \\
2007 & 1611 & $(1015) 170.3 \%$ & (7) $0.43 \%$ \\
2008 & 2936 & $(2340) 392.6 \%$ & (8) $0.27 \%$ \\
2009 & 2123 & $(1527) 256.2 \%$ & (3) $0.14 \%$ \\
\hline
\end{tabular}

Baby Deliveries in the Labour Room 596, 627, 1611, 2936 and 2123

The gross clientele turnovers for the whole hospital in each of these five years (2005 2009) were $76452,107884,128474,140147$ and 145127 (Figure 6), while mortalities from in-patients for the corresponding years were 284 (6\% of in-patients), 221 (3.64\%), 200 (1.68\%), $143(1.04 \%)$ and 127 (0.81\%), respectively (Figure 7). 


\section{Figure 6: Gross Clientele Turnover}

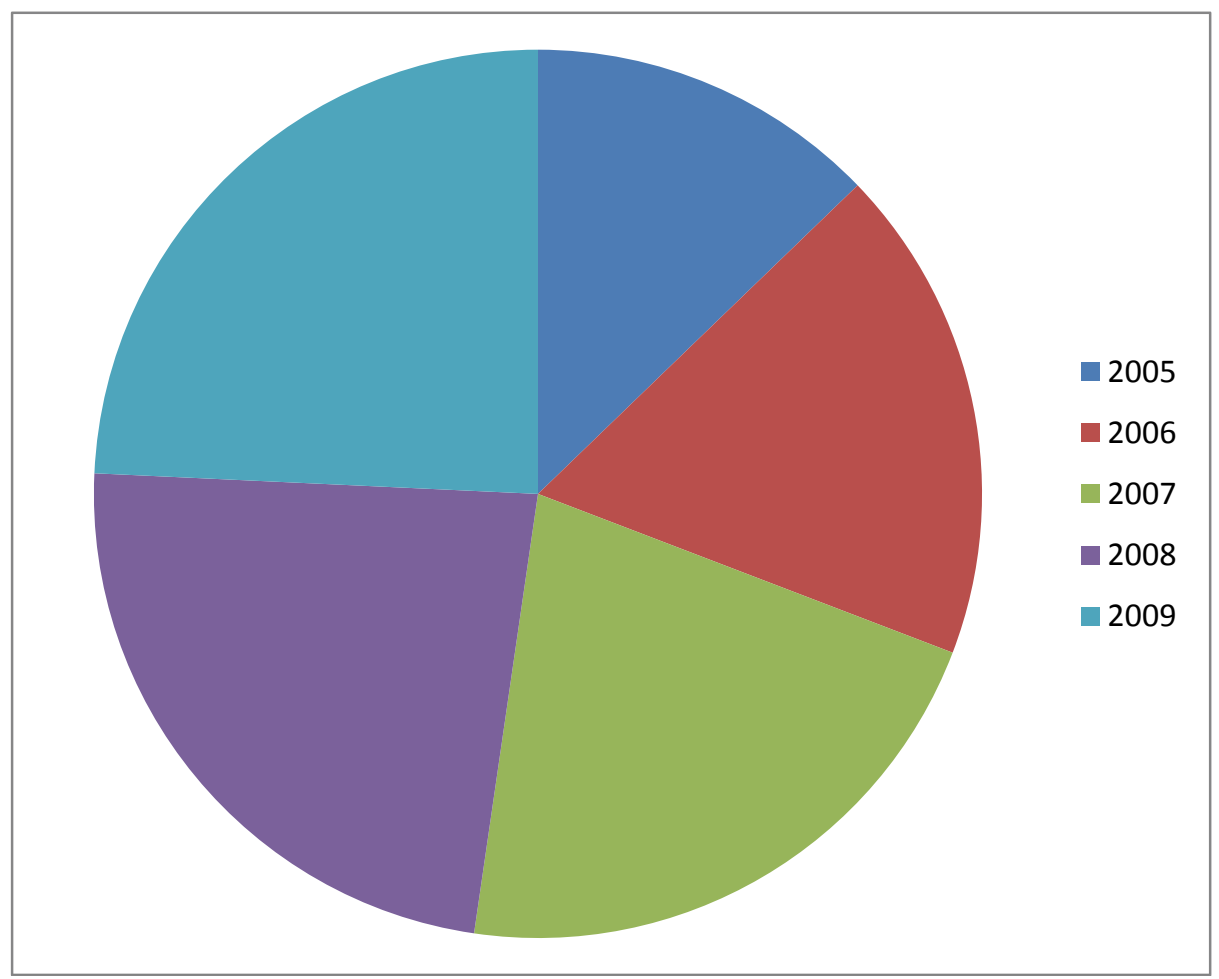

With the gross annual clientele turnovers of 107884, 128474, 140147 and 145127 from 2006 to 2009 in NAUTH, there were geometrically increasing figures of $41 \%$ ( $p$ <0.05), 68\% ( $p<0.05), 83.3 \%(p<0.05)$ and 89.8\% ( $p<0.05)$ compared to the 2005 annual figure of 76452 , respectively.

Both the difference in gross clientele turnover and Accident \& Emergency attendance, when subjected to analysis, were found to be statistically significant ( $p$ $<0.05$ ) in each of the years. 
Figure 7: In-Patient Mortality

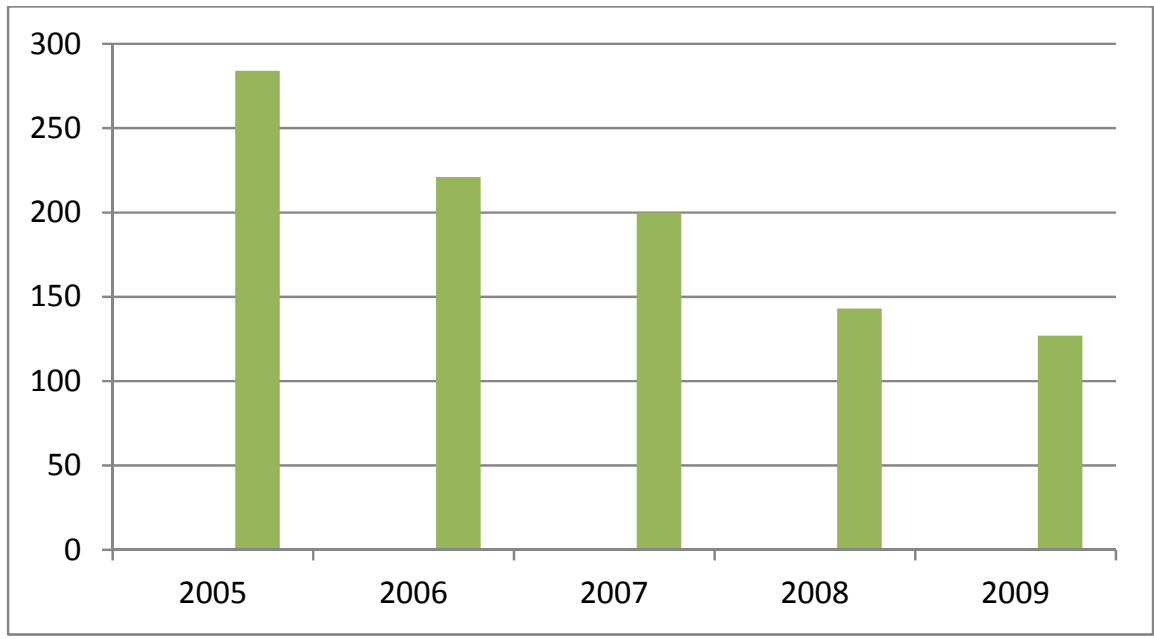

Within this same period, the maternal mortalities were 11 (1.84\%), 9 (1.43\%), 7 (0.43\%), 8 $(0.27 \%)$ and $3(0.14 \%)$, respectively (Table 3$)$.

\section{Discussion of Results}

With the inauguration of the SERVICOM Charter by the Federal Government of Nigeria, the Management of Nnamdi Azikiwe University Teaching Hospital Nnewi identified key areas that required re-evaluation and attention based on the submissions of every service unit and department, after an analysis of the Strengths, Weaknesses, Opportunities and Threats (SWOT) of each of the service areas.

A pre-SERVICOM Charter workshop, supervised by the Federal Government, was held in the various institutions nationwide to enable care providers enumerate their current service capacity and identify their impediments or challenges.

Then, based on their stated ideal objectives, risks, shortcomings and strengths, the institutional needs that would enable them to achieve their set objectives, were identified.

With the resolutions from the workshop, human and material resources were upgraded in order to address the identified risks and enhance the capacity of each service unit or department of the institution to attain these set goals. 
The changes employed in the Accident and Emergency Unit of NAUTH Nnewi included:

- the employment of more medical officers, nurses and other health personnel

- procurement of more diagnostic and therapeutic equipment

- availability of adequate supply of medications

- appointment of a new Head of Unit with a brief to enforce discipline and compliance with all the activities in the Unit

- daily (morning) audit of the clientele turn-over and treatment outcome in the Unit for the preceding 24 hours, by the hospital management

- installation of free communication lines for health personnel to easily make contact with their colleagues, superiors or hospital management round-theclock whenever there is an urgent need arising from care delivery

- waiver on hospital bills for all emergency cases until resuscitation/salvage is achieved or relatives who would make payment arrive

- direct line of feedback from the clients to the hospital management for whatever impression they make of the care they received

- 24-hour electric power supply; and

- $\quad$ structural renovation of sections of the Unit.

Following these reforms, the time lapse between the arrival of a client in the Accident and Emergency (A\&E) Unit and review by the doctor on call in the A\&E Unit was shortened to a maximum of 5 minutes compared to the previous scandalous records that got as long as 2 hours in some instances. Also, the maximum time lapse between the review of the client by the doctor on call in the A\&E Unit and the arrival of any specialist Unit on call that is required to attend to the same client, if there was a need for specialist attention, was statutorily fixed at 30 minutes. For the rest of the institution itself, a log register was introduced and strictly enforced to monitor the movement of Staff right from the moment of arrival for duties till the commencement of duty and time of departure. Appropriate sanctions were spelt out on erring Staff. Similar changes as in the 
A\&E Unit were also introduced in the Labour Room and Children's Emergency Room, all of which were regarded as the emergency flashpoints in the hospital's service delivery.

As soon as the protocols of the SERVICOM Charter were put in place, the attitude of our Staff began to change, and remarkably too. Whether it was solely from selfconviction or for fear of sanctions, it was not very clear, but for whatever reason it was, the positive change was rather dramatic. Every employee rushed to make it to the duty post every day before the attendance register was closed, and at the various service points, clients were given timely and polite attention; medications were readily available and no client was left unattended to merely on account of lack of funds.

Most importantly, clients and their relatives began to feel that they were being listened to and respected - a key aspect of what people value about healthcare, and which was noted to be similar to the experience reported in 2007 from Alaska, USA and other parts of the world where some health reforms were undertaken leading to a remarkably positive response (Eby 1998:89; Gottlieb et al., 2008:17; Kerssens 2004:18; Eby 2007:64). With the gross annual clientele turnovers of 107884, 128474, 140147 and 145127 from 2006 to 2009 in NAUTH Nnewi, it was evident that there were geometrically increasing patronage of $41 \%$ - $89.8 \%$ (all of which had p-values of <0.05), respectively, over the 2005 annual figure of 76452. In the A\&E Unit, the clientele attendance of 3988, 7034, 10503, 12224 and 14118 for the same period equally translated to rises of $76.4 \%(p<0.05), 163.4 \%(p<0.05), 206.5 \%(p<0.05)$ and $254 \%$ ( $p$ $<0.05)$, respectively over the 2005 figures. Both the differences in gross clientele turnover and $A \& E$ attendance when subjected to analysis were found to be statistically significant $(p<0.05)$ in each of the years.

Prior to 2005, the impression of NAUTH Nnewi clients and their relatives was that prompt and optimal care was more likely to be obtained in private clinics within Nnewi locality than in the Teaching Hospital; and their reasons bothered mostly on the attitude of the public health personnel and non-availability of medications notoriously reported on a frequent basis, from government-run health facilities. The WHO had previously noted that people became increasingly impatient with the inability of health services to deliver levels of national coverage that meet stated demands and changing needs, and with their failure to provide services in ways that correspond to their expectations (WHO 2008). Following this trend, therefore, it was explicable that patronage of government institutions in Nigeria in the decade preceding the SERVICOM Charter remained very low 
and in most cases, was confined to those clients who could not afford the bills of private facilities, or to victims of accidents whose identities and relatives were not known in the immediate post-octal period.

But, Nigeria was not alone in her predicaments and inadequacies because studies by Halman, et al., (2008:28), Millenson (2002), Davies (1999: 34) and Mullan and Frehywot (2007: 45), had equally shown that in many parts of the world, there were considerable scepticism about the way and the extent to which health authorities assume their responsibilities for health. Surveys had demonstrated a trend of diminishing trust in public institutions as guarantors of the equity, honesty and integrity of the health sector because on the whole, people expect their health authorities to work for the common good, do this well, and do so with foresight (Gilson 2003). The increased patronage noted after the introduction of SERVICOM appeared, therefore, to indicate a restoration of public confidence in the capacity of the hospital to provide desirable services. And this seemed to cut across the entire service points of the index hospital. In the Operating Theatre, some of which clients pass through the A\&E Unit, figures rose by $32 \%(p<0.05)$, $270.2 \%(p<0.05), 313.8 \%(p<0.05)$ and $463.6 \%(p<0.05)$, when compared to the 2005 statistics, just like in the Labour Room where delivery of new babies rose remarkably by $170.3 \%(p<0.05), 392.6 \%(p<0.05)$ and $256.2 \%(p<0.05)$, respectively for 2007, 2008 and 2009 . The $5.2 \%$ rise recorded in 2006 was, however, not statistically significant on analysis $(p>0.05)$.

Perhaps, even more compelling than the absolute figures of patronage, were the mortality rates amongst the In-patients and pregnant mothers, both of which were on a persistent decline despite the rise in total clientele turnover. Mortality rates for Inpatients in the five years 2005-2009 were 284 (out of 4718 admissions), 221 (6067 admissions), 200 (11874), 143 (13750) and 127 (15650), which translated to 6\%, 3.64\%, $1.68 \%, 1.04 \%$ and $0.81 \%$ of all admitted cases, respectively. When the post-SERVICOM mortality rates were compared to 2005 (6\% of 4718$)$, the mortality rates showed a marked progressive reduction by $39.3 \%(p<0.05)$ in $2006,72 \%(p<0.05)$ in $2007,82.7 \%$ $(p<0.05)$ in $2008(p<0.05)$ and $86.5 \%(p<0.05)$ in 2009 , respectively; all of which were statistically significant.

After an assessment of the available data, it was observed that from 2006, when compared to the pre-SERVICOM Charter era, there were: 
The Effect of Service Compact (SERVICOM) on Service Delivery in NAUTH Nnewi 125

- $\quad$ progressive increase in clientele patronage / turnover in all the service sectors $A \& E$, Out-patient, In-patient, Operating Theatre, Labour Room, Laboratories, etc.

- $\quad$ progressive decrease in absolute mortality rates of the In-patients per annum

- $\quad$ progressive decrease in maternal mortality rates per annum

- much greater decline in relative mortality rates for all the in-patients and pregnant mothers per annum.

These findings strongly supported the fact that the introduction of the SERVICOM Charter stimulated several positive changes, and thereby re-positioned the index tertiary health institution towards a much better satisfaction of the demands of our clientele. They provided the answer to the question thus: the SERVICOM Charter has made the desired impact on care delivery in our health institution; even though it should be stated unequivocally that there is still a lot of room for more improvement.

It is worth noting that beyond attitude, the role of quality personnel, modern diagnostic and therapeutic equipment, and adequate remuneration of workers, would never be over-emphasized. Attitude alone may not be enough to sustain these massive gains for too long because it is only a portion of the whole armamentarium for a successful health care delivery system. Increasing Nigeria's annual budgetary allocation to health from the present $2 \%$ to the WHO recommended $15 \%$ as affirmed at the Abuja Accord holds the surest key. Regular quality assurance of the human and material resources should be a complementary aspect of the project of better service delivery in all sectors of the Nigerian economy, most importantly, the health sector. More so, a host of other fairly low-cost policies (e.g. enhanced provision of water, medical drugs, or AIDS education/care) have been reported to lead to dramatic improvements in life expectancy in developing countries, and these should be given priority by the various governments in Nigeria, as well (Audrey and Graves, 1990).

\section{Conclusions}

It is obvious that the structural and attitudinal changes introduced by the SERVICOM Charter, brought a very significant improvement in all the performance indices of the service units and departments of Nnamdi Azikiwe University Teaching Hospital Nnewi, 
and thus, contributed to the improved care delivery to their clients. Perhaps, one of the most likely handicaps that could stall or reverse these gains is the non-sustenance of the current momentum, but which if sustained and the introduced changes improved upon, health care delivery despite its various challenges would most likely continue to improve, and the life expectancy of the average Nigerian would record a rise.

\section{Recommendations}

Going by the success recorded by the SERVICOM Charter in the first 5years after the adoption, the following recommendations are hereby made in order to sustain and build on this success and hope that in the health sector, Nigerian public servants would give our citizens the optimum service they deserve and crave for, just like in the developed countries of the world:

- The SERVICOM Charter project should be sustained.

- Supervision and control of the SERVICOM Charter project should be intensified in order to ensure that the Nigerian factor of service-fatigue would not supervene in care delivery in the near future.

- An independent SERVICOM Charter Commission should be established as a part of Federal Government Parastatals and extended in authority to the various States of Nigeria just like the case with the National and State AIDS/HIV Control Agencies which are represented all the way down the 3 tiers of government.

- Mouth-watering incentives should be apportioned, on an annual basis, to all institutions that excel in efficient service delivery to their clients, whereas, stiff penalties should be meted out to poor performers, and both events given wide national media coverage.

- The National Health Insurance Scheme (NHIS) should be revised to cover the whole spectrum of diseases available in Nigeria, in order not to stigmatize some disease sufferers in our country, where healthcare delivery is purely based on "cash and carry."

- The Federal Government should endeavour to improve on her annual allocation to health, in line with the Abuja Accord as recommended by the WHO, to at 
least $15 \%$ of the National Budget, and reduce her undue expenditures on defence.

If these recommendations are followed through, there is no doubt that Nigerians would become healthier people and the abysmal indices that have characterized our Health sector, especially the depreciating life expectancy of the average citizen would be arrested and progressively reversed to give Nigerians optimum health....and wealth, since health is wealth.

\section{List of References}

- Abah, N.C. 1997. Public Personnel Administration, Enugu: Joen Associates.

- AFRICA/NigERIA MASTERWEB 2006. Special Feature on Nigeria Census Figures. http://www.africamasterweb.com\&http://www.nigeriamaster web.com

- Akpala, A. 1990. Management: An Introduction and the Nigerian Perspective (Published by Department of Business Management, Faculty of Business Administration, UNEC. In: Amobi, Dennis Success C and Nnabuife Kate Ezinna N. Management: An Operational Perspective. J'Goshen Publishers and Printers

- Akuezilo, EO and Agu, N. 2002. Research and Statistics in Education and Social Sciences, Methods and Applications. Awka: Nuel Centi Publishers and Academic Press Ltd.

- Audrey B, Graves PE. 1990. Predicting Life Expectancy: A Cross-Country Empirical Analysis. file://localhost/C:/Documents and Settings/Life Expectancy2.htm

- Central Intelligence Agency. 2000. The World Fact Book. https://www.cia.gov/library/publications/the-world-factbook/geos/ni.html

- Chukwuemeka EEO. 2006. Research Methods and Thesis Writing - A Mutli-disciplinary Approach. HRV Publishers, Enugu, Nigeria. 3:30-41.

- Davies H. 1999. Failing public trust in health services: Implications for accountability. Journal of Health Services Research and Policy, 4:193-194.

- Eby D. 2007. Primary care at the Alaska Native Medical Centre: a fully deployed "new model" of primary care. International Journal of Circumpolar Health, 66(Suppl. 1):4-13. 
- Eby D.1998. Integrated primary care. International Journal of Circumpolar Health, 57 (Suppl. 1):665-667

- Flippo, E.1981. Personnel Management, London. McGraw Hill Book Co.

- Gilson L.2003. Trust and the development of health care as a social institution. Social Science and Medicine, 2003, 56:1453-1468.

- Global Security: 1983 Buhari Coup. http://www.globalsecurity.org/military/world/war/ nigeria2.htm

- Gottlieb K, Sylvester I, Eby D.2008. Transforming your practice: what matters most? Family Practice Management, 2008, 15:32-38.

- Halman L 2008. Changing values and beliefs in 85 countries. Trends from the values surveys from 1981 to 2004. Leiden and Boston, Brill, 2008 European values studies 11; http://www.worldvaluessurvey.org/, accessed 2 July 2008.

- Health in Africa. 2000. http://en.wikipedia.org/w/index.php?title=Health _care _in_Nigeria\&oldid $=493819155$

- Kerssens JJ, et al, 2004. Comparison of patient evaluations of health care quality in relation to WHO measures of achievement in 12 European countries. Bulletin of the World Health Organization, 2004 82:106-114

- Koontz and O’Donnel. 1968. Principles of Management: An Analysis of Managerial Functions. New York, MacGraw Book Co.

- Kuru Declaration. 2003. National Assembly Inaugural Speech Service Delivery In Nigeria: A Roadmap - Time To Deliver; President's Remark, Memorandum by the President of the Federal Republic of Nigeria; Federal Executive Council Report on the Establishment of Ministerial SEVICOM Units. SERVICOM Office, http://www.servenigeria.com/misc/wendyreport.pdf.

- Millenson ML 2002 How the US news media made patient safety a priority. British Medical Journal 2002; 324:1044.

- Monye Felicia; 2010. 'An Appraisal of the National Health Insurance Scheme of Nigeria', Commonwealth Law Bulletin, 32:3 415-427

- Muataz A and Shawqi S 2006. Outcome of adolescent pregnancy at a university hospital in Jordan. Archive Gynaecology and Obstetrics, 273:207-210.

- Mullan F, Frehywot S. 2007. Non-physician clinicians in 47 sub-Saharan African Countries 
The Effect of Service Compact (SERVICOM) on Service Delivery in NAUTH Nnewi 129

- National Health Accounts .2008. World Health

Organization,http//www.who.int/nha/country/en/index.html, accessed May 2008.

- Nnewi North Local Government .2008. The Profile of Nnewi North Local Government Area. Information Unit, Nnewi North Local Government Area, Nnewi

- Orga, Christopher .2002. "The Challenges of Human Resources Management and Development in Nigerian Local Governments". A Paper Delivered at a Workshop in Modotel Hotels Enugu. In: Chukwuemeka, Emma (2004). Principles and Practice of Human Resources and Personnel Management in Nigeria; Enugu: HRV Publishers.

- Stoner, James AF 1978. Management. London; Prentice-Hall Inter Inc; 1978.

- THIS DAY NEWSPAPERS, 2009 Osotimehin Canvasses Health Sector Reform. http:// www.thisdayonline.com/nview.php.

- UNDP. Human Development Report, 2006. Human Development Indicators, Country Fact Sheet: Nigeria p 29-212.

- U.S. Amb Robin Reneé Sanders: 2008. Isaac Moghalu Foundation Leadership Lecture Nigerian Institute of International Affairs. Lagos, April 23, 2008 file://localhost/E:/USAmbSpeech.htm.

- Vanguard Media Limited. 2005 Vanguard Comment Nigeria's Lower Life Expectancy 1998 2005.

- Wendy Thomson 2007. Delivering Service in Nigeria: A Roadmap; Office for Public Service Reform, United Kingdom. http://www.servenigeria.com/misc /wendyreport.pdf

- WHO. 2008. World Health Report: Primary Health Care - Now more than ever 14 October 2008, Geneva.

- World Health Organization.2004. Selected National Health Accounts Indicators for all Member States http://www.who.int/whr/2004/annex/en/index.html

\section{AUTHORS' CONTACT:}

EMEULU, Jude Kennedy

College of Medicine

Nnamdi Azikiwe University Email:

jk.emejulu@unizik.edu.ng
MUO, M.C.

Dept of Public Admin Nnamdi Azikiwe University Email: mc.muo@unizik.edu.ng
Chukwuemeka, E.E.0.

Dept of Public Admin Nnamdi Azikiwe University Email:

ee.chukwuemeka@unizik.edu.ng 